Instructions for authors, subscriptions and further details:

\title{
http://rasp.hipatiapress.com
}

\section{Género y Generación: Influencia en la Implicación Política de los Mayores en España}

Emilia Riesco Vázquez ${ }^{1}$

1) Universidad de Salamanca

Date of publication: January $30^{\text {th }}, 2016$

Edition period: January 2016 - July 2016

To cite this article: Riesco, E. (2016). Género y Generación: Influencia en la Implicación Política de los Mayores en España. Research on Ageing and Social Policy, 4(1), 96-133. doi: 10.17583/rasp.2016.1762

To link this article: http://doi.org/10.17583/rasp.2016.1762

\section{PLEASE SCROLL DOWN FOR ARTICLE}

The terms and conditions of use are related to the Open Journal System and

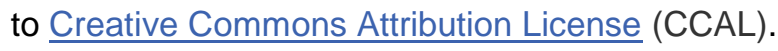




\section{Género y Generación: Influencia en la Implicación Política de los Mayores en España}

Emilia Riesco Vázquez

Universidad de Salamanca

\section{Resumen}

España experimenta un proceso de envejecimiento demográfico desde hace varias décadas que la sitúan actualmente como uno de los países más envejecidos del mundo. Este proceso lleva asociados cambios en las características de las diferentes generaciones, que serán especialmente relevantes en las cohortes futuras de personas mayores. Concretamente, el envejecimiento de la población alterará los patrones de implicación política. Este trabajo analiza la influencia que pudieran tener tanto las cuestiones de género como la generación en el comportamiento político de las personas mayores. Se realiza un estudio relacional basado en la explotación de datos del Centro de Investigaciones Sociológicas. Los hallazgos del mismo evidencian que género y generación introducen importantes diferencias tanto en el interés como en la participación social. Se concluye aportando averiguaciones acerca de la importancia que tiene la pertenencia a una determinada generación en lo que respecta a la implicación en los asuntos públicos, frente a consideraciones frecuentes que le atribuyen un mayor protagonismo a la edad. Asimismo, se aporta información relevante acerca de la próxima generación de mayores, que no sólo tendrá una gran importancia numérica sino que, plausiblemente, asumirá un importante protagonismo social.

Palabras clave: participación política, género, generación, compromiso cívico 


\section{Gender and Generation: Influence on the Political Implication of the Elderly in Spain}

Emilia Riesco Vázquez

Universidad de Salamanca

\section{Abstract}

Spain suffers a demographic ageing process for several decades now, and today it is one of the most aged countries in the world. This process entails changes in the characteristics of different generations, some of which will be especially relevant in the future cohorts that advance into mature age. Specifically, the ageing of the population alters the patterns of political implication. This work analyzes the influence that gender questions and generation may have in the political behavior of the elderly. We present a relational study based on the data provided by the Centro de Investigaciones Sociológicas (Center for Sociological Research). Our findings prove that gender and generation introduce important differences in interest as well as in social participation. We also provide conclusions on the importance of belonging to one specific generation with regard to the implication in public affairs, as opposed to frequent considerations that tend to grant more preeminence to age. Similarly, we provide relevant information on the next older generation, who will not only be important in number, but also will conceivably take on a very important main social role.

Keywords: political participation, gender, generation, civil engagement 


\section{Emilia Riesco-Género, Generación e Implicación Política}

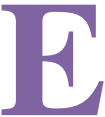

spaña ha sufrido un proceso de envejecimiento demográfico desde hace varias décadas que no sólo ha cambiado la estructura por edades de la población, sino que también lleva asociados otros cambios en las características de las generaciones que la integran (Pérez Díaz, Abellán y Ramiro, 2012). La vejez ha dejado de tener connotaciones negativas asociadas a sí misma y ha empezado a remplazarse por un concepto positivo (Trinidad, 2006) que todavía cambiará mucho más en los años sucesivos. Cada nueva generación se ha visto incrementada con un capital humano superior, ya que, como afirman Pérez Díaz et al. (2012), el mal llamado envejecimiento demográfico es realmente el resultado de la modernización demográfica. El envejecimiento de la población es el mayor logro social de la humanidad. Este proceso va configurando generaciones cada vez mejor dotadas que, a medida que se van incorporando a la vejez, muestran una transformación en las características, actitudes y comportamientos de las personas mayores, representando un gran potencial para la sociedad en su conjunto. Por todo ello es necesario que se aborde el estudio de esta categoría de edad desde el reconocimiento de las crecientes potencialidades, no sólo para sí misma, sino para el conjunto de la sociedad. La modernización sociodemográfica va a hacer posible que los mayores sean cada vez más activos, y no serán sólo receptores de recursos, sino que serán actores protagonistas cada vez más importantes.

Desde el punto de vista de la Sociología política, las personas mayores en España se han convertido en una fuerza electoral de primer orden (el 23,5\% del censo electoral en 2011) (INE, 2013), que podrían determinar el resultado de cualquiera de las elecciones. Si bien parece ser que los mayores no actúan como un nuevo actor político colectivo (Durán, 2002), sí parece existir una proporción importante de ellos que desearían estar presentes en distintos ámbitos de la vida pública (Pérez Ortiz, 2009a; Riesco, 2009), lo que lleva a plantearnos, como objeto de este artículo, el análisis de la influencia del género y la generación en la implicación política de los mayores en España con el fin de descubrir su potencial.

El manuscrito presentado se inserta dentro de un trabajo más amplio que analiza el compromiso cívico de las personas mayores en España. La calidad de la democracia está directamente relacionada con el ejercicio activo de los derechos políticos y civiles de su ciudadanía, es decir, con su implicación política. Habermas (1998) y Putnam (1993) afirman que cuanto mayor es la participación de los ciudadanos, mayor es el control que se ejerce sobre los 
representantes políticos, lo que implicará una mayor responsabilidad en el ejercicio del poder (Putnam, 1993; 2003; Torcal, 2006; Durán, 2007b). Para Putnam, el compromiso cívico o capital social de una comunidad radica en el interés que manifiesta en los asuntos públicos, en su participación electoral y en la intensidad y densidad de su vida asociativa (1993; 2003).

El objeto de este estudio es abordar las dos primeras dimensiones, analizar el interés por la política y la participación electoral de los mayores. Se realiza una comparación en función de las etapas vitales o de desarrollo de los sujetos. Concretamente, nos referimos a las denominadas generaciones del desarrollo (55 a 64 años) y de la postguerra (65 y más años) (Gil Calvo, 2003) y se indaga sobre la influencia del género en las mismas. Pretendemos dar respuesta a algunos de los interrogantes que plantea en el terreno político el envejecimiento de la población.

Las hipótesis que orientan nuestro trabajo están basadas en las teorías del envejecimiento activo, de la participación y de la estratificación por edades (Riley, 1985; 1988). Este enfoque destaca las relaciones entre los cambios estructurales y la diferenciación por cohortes. Parte de la idea de que la sociedad se compone de generaciones sucesivas de individuos que envejecen de distinta manera. Cada generación debe afrontar un conjunto de acontecimientos y cambios relacionados con el momento socio-histórico en el que vive. Riley considera que la variable edad incide en función de las características de su cohorte, que va más allá de los cambios derivados del proceso de envejecimiento. El planteamiento del envejecimiento activo hace referencia a una participación continua de las personas mayores en las cuestiones sociales y respalda su responsabilidad para ejercer su participación en el proceso político.

\section{Viejos y Nuevos Paradigmas de la Política}

El fenómeno del envejecimiento, en general, no se aborda desde presupuestos democráticos ligados a la participación política, sino que más bien se incide en cuestiones de gestión y financiación, desde una concepción moderna de lo político (Durán, 2002). En este trabajo, se va a incidir en el proceso democrático.

Con la llegada del nuevo siglo y de la sociedad de la Información, entre las muchas cosas que han cambiado en la sociedad, una de ellas es el sentido de la participación social. Las sociedades de hoy en día reclaman modelos de 


\section{Emilia Riesco - Género, Generación e Implicación Política}

participación distintos de los que hemos conocido hasta ahora, es decir, de los que demandaba la Modernidad Tradicional. Una de las características de la Modernidad Tradicional es la clara distinción entre sujeto y objeto de la participación social y política. Podríamos decir que toma fuerza la máxima del despotismo ilustrado de "todo para el pueblo, pero sin el pueblo", llegándose en la práctica a que las organizaciones y agentes considerados socialmente como políticos, a través de sus actuaciones, se conviertan en sujetos y protagonistas de la acción política, mientras que los agentes sociales y la ciudadanía en general quedan únicamente como destinatarios de esas políticas, es decir, como objetos de dicha acción. La ruptura entre sujeto y objeto en un sistema capitalista lleva también a la invisibilidad de los agentes considerados como económicamente no productivos, como en el caso de las personas mayores. La Declaración Política de la Asamblea de Vejez y Envejecimiento, en Madrid en 2002, se corresponde con el nuevo paradigma de participación. Desde el planteamiento moderno de la vejez, se piensa en lo que la política institucionalizada puede hacer por los mayores, pero sin tener en cuenta el planteamiento político de la participación de este colectivo como tal (Durán, 2002). Se considera a los ancianos como clientes del Estado y como tal se les atiende. Las personas mayores han sido consideradas una clientela electoral a la que dirigirse los partidos políticos antes de cada periodo electoral.

Por otro lado, para Castells, las nuevas tecnologías de la información permiten la liberación del tiempo (2000) y confieren una nueva temporalidad que denomina el tiempo atemporal que se manifiesta en todo el ámbito de la experiencia humana, siendo la forma emergente del tiempo social. Esta concepción enlazaría con el surgimiento, en palabras de Offe (1988), de un nuevo paradigma de la política, así como con los estudios de Inglehart (1998) sobre los valores postmaterialistas y las cuestiones políticas postmodernas que buscan alternativas a las formas institucionalizadas de representación y participación políticas. Para Beck, sería el paso a la "modernización reflexiva" (Beck, Giddens y Lash, 1997), donde lo político se manifiesta más allá de las responsabilidades y las jerarquías formales. Al mismo tiempo, Innerarity (2006) señala que se ha producido una modificación del marco de condiciones a partir del cual los temas eran diferenciados como públicos o privados y tratados como tales. Lo que se considera público o privado está sometido a cambios históricos y a decisiones políticas, por eso exige una continua redefinición. En la 
actualidad, las demandas de equidad exigen una nueva formulación de igualdad. Las diferencias han de ser reconocidas en igualdad, pero en tanto que diferencias; por ello, las personas mayores, que reclaman una mayor presencia en la política, no demandan privilegios. Estas y otras teorías coinciden en señalar que podríamos estar asistiendo a la aparición de un nuevo actor político colectivo, del cual los mayores podrían constituir una parte muy importante. Retomando los argumentos de Castells, en la sociedad emergente se está debilitando el ciclo vital ordenado en torno a categorías sociales, entre las cuales la educación, el tiempo laboral, las trayectorias profesionales y la jubilación se convirtieron en supremas. Las razones para esta nueva tendencia están en la cronología variable del tiempo laboral. Mientras que antes la ancianidad se consideraba un último estadio homogéneo de la vida, al que se accedía por la jubilación, ahora es un universo muy diverso que se extiende hacia grupos más jóvenes y más mayores y redefine el ciclo vital obligando a establecer una distinción entre varios grupos de edad, cuyas diferencias reales dependerán en gran modo del capital social, cultural y relacional acumulado durante sus vidas (Castells, 2000; Guillemard, 1988).

\section{Metodología}

Cada una de las dimensiones estudiadas, interés por la política y participación electoral, son susceptibles de medirse a través de indicadores. Para cada uno de ellos, hemos realizado tablas de contingencia con el fin de analizar la incidencia de la variable sexo, haciéndolo tanto intragrupo como intergrupo de cada una de las dos categorías de edad consideradas. El interés por la política se infiere de la propia declaración acerca de la misma, de la percepción de la complejidad que tienen de los asuntos políticos, de la exposición a la información de actualidad política y de las conversaciones mantenidas sobre la misma. La participación electoral es observable, así como el sentido de la misma.

El análisis empírico se basa en la explotación de datos del Centro de Investigaciones Sociológicas (CIS), utilizándose el barómetro de opinión de abril de 2009 ( $\mathrm{n}^{\circ}$ 2798), los estudios postelectorales de las Elecciones Generales y Autonómicas de Andalucía del 2004 y 2008 (nº 2559 y n 2757 respectivamente) y de las Elecciones al Parlamento Europeo de 2009 (n 2807), así como el estudio de las Elecciones Generales de 2011 (n 2920). 


\section{Emilia Riesco - Género, Generación e Implicación Política}

La población objeto de nuestro estudio son las personas de 55 o más años de edad, divididas en dos subgrupos: de 55 a 64 años y de 65 y más. Esta agrupación obedece al interés por analizar y comparar el comportamiento político de cada una de esas dos categorías de edad, ya que el grupo de menor edad formará parte de la generación de mayores inmediatamente por venir, cuyas características probablemente distarán mucho de los estereotipos que hoy atribuimos a la vejez. Cada generación es distinta de las demás y marca a sus miembros con un cierto "determinismo generacional" debido a sus características comunes: el tamaño relativo, la educación recibida, la incorporación a la actividad laboral, el calendario de formación de familia, etc. (Gil Calvo, 2003). Las personas entre 55 y 64 años de edad, en el momento del estudio, nacieron entre los años 1945 y 1954, pertenecen a la denominada por Gil Calvo generación del "desarrollo" mientras que los de 65 y más años pertenecen a las generaciones de principios del siglo XX.

\section{Resultados}

\section{Interés por la Política}

El interés por la política es uno de los aspectos que permite identificar la implicación cívica de la ciudadanía. Hemos analizado varios indicadores que podrían aportar información relevante sobre esta dimensión; aquí haremos referencia solamente a los que muestran mayores diferencias entre ambos subgrupos en función del género.

Percepción de la complejidad de la política. El análisis de los datos del estudio 2807 del CIS (p. 26) muestra diferencias claramente significativas entre los distintos grupos de edad a la hora de calificar la política como difícil de entender. Concretamente, la política aumenta su complejidad a medida que aumenta la edad de las personas (Tabla 1).

$\mathrm{El}$ análisis comparativo entre los grupos de mayor edad revela diferencias generacionales claras. Mientras para el 70,5\% de la generación de la guerra civil la política resulta un tema complejo, disminuye al 55,8\% para la generación del desarrollo.

El análisis en función del sexo muestra que en el grupo de 55 a 64 años son las mujeres las que principalmente están de acuerdo en considerar la política como un tema complicado $(64,9 \%)$, comparándolas con los varones 
de este mismo grupo de edad donde sólo un 46,6\% está de acuerdo con esta afirmación $(\chi 23=16,278 \mathrm{p}=.001)$. Al realizar el mismo análisis en el grupo de edad de 65 años y más, encontramos también diferencias significativas $(\chi 23=52,375 \mathrm{p}=.000)$, y en el mismo sentido que el análisis anterior, es decir, las mujeres son las que consideran la política como un tema complejo (Tabla 1). Asimismo, también obtenemos un efecto significativo para la variable generacional sólo en las mujeres $(\chi 23=31,263 \mathrm{p}=.000)$. Así, las mujeres de 65 y más años son las que consideran la política como un tema complejo, en comparación con sus pares de 55 a 64 años.

Tabla 1

Percepción de la complejidad de la política por grupos etarios y sexo

La política como un tema complicado (\%)

\begin{tabular}{|c|c|c|c|c|c|c|c|}
\hline $\begin{array}{l}\text { Orientación } \\
\text { del contraste }\end{array}$ & $\begin{array}{l}\text { Categorías } \\
\text { de Control }\end{array}$ & $\begin{array}{c}\text { Grupo de } \\
\text { Comparación }\end{array}$ & $\begin{array}{l}\text { Muy de } \\
\text { acuerdo }\end{array}$ & $\begin{array}{c}\text { De } \\
\text { acuerdo }\end{array}$ & $\begin{array}{c}\text { En } \\
\text { desacuerdo }\end{array}$ & $\begin{array}{c}\text { Muy en } \\
\text { desacuerdo }\end{array}$ & $\begin{array}{c}\text { TOTAL } \\
(\mathrm{N})\end{array}$ \\
\hline \multirow{4}{*}{$\begin{array}{l}\text { Sexo / } \\
\text { Edad }\end{array}$} & \multirow{2}{*}{ Hombres } & 55 a 64 & 12,7 & 35,9 & 40,6 & 10,8 & 315 \\
\hline & & 65 y más & 15,0 & 43,8 & 33,3 & 7,8 & 306 \\
\hline & \multirow{2}{*}{ Mujeres** } & 55 a 64 & $18,1^{*}$ & 46,8 & $30,0 *$ & 5,1 & 237 \\
\hline & & 65 y más & $34,0 *$ & 45,0 & $14,8 *$ & 6,2 & 420 \\
\hline \multirow{4}{*}{$\begin{array}{l}\text { Edad / } \\
\text { Sexo }\end{array}$} & \multirow{2}{*}{55 a $64 * *$} & Hombres & $12.7 *$ & $35,9 *$ & $40,6^{*}$ & $10,8 *$ & 315 \\
\hline & & Mujeres & $18,1^{*}$ & $46,8 *$ & $30,0 *$ & $5,1 *$ & 237 \\
\hline & \multirow{2}{*}{$\begin{array}{l}65 y \\
\text { más** }\end{array}$} & Hombres & $15,0 *$ & 45,8 & $33,3 *$ & 7,8 & 306 \\
\hline & & Mujeres & $34,0 *$ & 45,0 & $14,8 *$ & 6,2 & 420 \\
\hline
\end{tabular}

* Residuos estandarizados corregidos mayor en valor absoluto a 1,96. / ** Significancia estadística al 0,05

Importancia de la política en la vida de las personas. En el análisis de las diferencias entre los grupos de edad y la importancia que le otorgan a la política (CIS, estudio 2798, p. 11), encontramos que no son significativas $(\chi 24=7,869 \mathrm{p}=.091)$. Sin embargo, el análisis del sexo y la consideración del impacto de la política en la vida cotidiana descubren que los varones consideran la política como un tema medianamente importante $(43,7 \%)$, 


\section{Emilia Riesco - Género, Generación e Implicación Política}

mientras que para las mujeres es un tema poco relevante en sus vidas $(44,4 \%)$ (Tabla 2$)$.

El estudio concreto de la interacción entre las variables grupo de edad de la generación del desarrollo y de la guerra civil, el sexo y la importancia de la política en sus vidas, considerando la edad como variable moderadora, muestra que existen diferencias significativas sólo para el grupo de edad de 65 años y más $(\chi 22=9,077 \mathrm{p}=.01)$, es decir, las mujeres de 65 años y más consideran que la política no es un tema relevante en sus vidas $(47,2 \%)$, en comparación con los varones de este mismo grupo de edad, quienes mencionan que la política es un tema moderadamente importante $(42,9 \%)$. Ahora bien, cuando consideramos la variable sexo como moderadora y hacemos la comparación entre las mujeres y varones de distintos grupos de edad, no se observan diferencias significativas para ninguno de los dos sexos. Por tanto, la diferencia de la importancia otorgada a la política es fundamentalmente un tema de género, y sólo dentro del grupo de 65 y más años.

Tabla 2

Importancia de la política según grupos etarios y sexo

Importancia de la política (\%)

Orientación Categorías Grupo de Poco o nada Medianamente Muy TOTAL

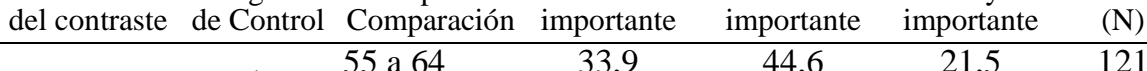

\begin{tabular}{|c|c|c|c|c|c|c|}
\hline \multirow{4}{*}{$\begin{array}{l}\text { Sexo / } \\
\text { Edad }\end{array}$} & \multirow{2}{*}{ Hombres } & 55 a 64 & 33,9 & 44,6 & 21,5 & 121 \\
\hline & & 65 y más & 32,5 & 42,9 & 24,5 & 163 \\
\hline & \multirow{2}{*}{ Mujeres } & 55 a 64 & 40,3 & 33,1 & 26,6 & 124 \\
\hline & & 65 y más & 47,2 & 29,2 & 23,6 & 178 \\
\hline \multirow{4}{*}{$\begin{array}{c}\text { Edad / } \\
\text { Sexo }\end{array}$} & \multirow{2}{*}{55 a 64} & Hombres & 33,9 & 44,6 & 21,5 & 121 \\
\hline & & Mujeres & 40,3 & 33,1 & 26,6 & 124 \\
\hline & \multirow{2}{*}{$\begin{array}{l}65 \mathrm{y} \\
\text { más** }\end{array}$} & Hombres & $32,5 *$ & 42,9* & 24,5 & 163 \\
\hline & & Mujeres & $47,2 *$ & $29,2 *$ & 23,6 & 178 \\
\hline
\end{tabular}

*Residuos estandarizados corregidos mayor en valor absoluto a 1,96. / ** Significancia estadística al 0,05. 
Frecuencia con la que se habla de política. Puede saberse también la importancia e interés por la política en función de la frecuencia con que se habla o discute de ella, así como de la exposición mediática a noticias y otras informaciones de actualidad.

Hablar de política con los amigos. La comparación de la frecuencia con la que hablan de política con sus amigos entre los distintos grupos de edad indica que los adultos de 35 a 54 años son los que más hablan de política con sus amigos (52,8\%), en comparación con los jóvenes (18 a 34 años) (50,1\%) y los adultos mayores y ancianos (55 años y más) (35,7\%).

La comparación entre la generación del desarrollo y de la guerra civil confirma la tendencia descrita anteriormente; es decir, las personas de entre 55 y 64 años conversan sobre política al menos algunas veces con sus amigos, mientras que las personas de más de 65 años, en su mayoría, nunca lo hacen (Tabla 3).

Tabla 3

Frecuencia con la que se habla de política con los amigos según grupos etarios y sexo

Frecuencia con la que se habla de política con los amigos $(\%)$

\begin{tabular}{|c|c|c|c|c|c|c|c|}
\hline $\begin{array}{l}\text { Orientación } \\
\text { del contraste }\end{array}$ & $\begin{array}{l}\text { Categorías } \\
\text { de Control }\end{array}$ & $\begin{array}{c}\text { Grupo de } \\
\text { Comparación }\end{array}$ & $\begin{array}{c}\text { A } \\
\text { menudo }\end{array}$ & $\begin{array}{l}\text { Algunas } \\
\text { veces }\end{array}$ & Raramente & Nunca & $\begin{array}{l}\text { TOTAL } \\
\text { (N) }\end{array}$ \\
\hline \multirow{4}{*}{$\begin{array}{l}\text { Sexo / } \\
\text { Edad }\end{array}$} & \multirow{2}{*}{ Hombres** } & 55 a 64 & 15,1 & $39,0 *$ & 27,7 & $18,2 *$ & 159 \\
\hline & & 65 y más & 11,9 & $23,3 *$ & 33,3 & $31,4^{*}$ & 210 \\
\hline & \multirow{2}{*}{ Mujeres** } & 55 a 64 & 9,2 & $30,7 *$ & 27,6 & $32,5^{*}$ & 163 \\
\hline & & 65 y más & 5,7 & $17,7 *$ & 21,2 & $55,5^{*}$ & 283 \\
\hline \multirow{4}{*}{$\begin{array}{c}\text { Edad / } \\
\text { Sexo }\end{array}$} & \multirow{2}{*}{55 a $64 * *$} & Hombres & 15,1 & 39,0 & 27,7 & $18,2 *$ & 159 \\
\hline & & Mujeres & 9,2 & 30,7 & 27,6 & $32,5 *$ & 163 \\
\hline & \multirow{2}{*}{65 y más** } & Hombres & $11,9 *$ & 23,3 & 33,3* & $31,4^{*}$ & 210 \\
\hline & & Mujeres & $5,7 *$ & 17,7 & $21,2 *$ & $55,5^{*}$ & 283 \\
\hline
\end{tabular}

*Residuos estandarizados corregidos mayor en valor absoluto a 1,96. / ** Significancia estadística al 0,05. 


\section{Emilia Riesco - Género, Generación e Implicación Política}

La misma tendencia generacional se repite cuando se considera la variable sexo. Ahora bien, cuando ahondamos en el análisis comparativo en función del sexo para cada grupo de edad, observamos diferencias significativas a favor de los hombres tanto para el grupo de 55 a 64 años $(\chi 23=10,350 \mathrm{p}=.016)$, como para el de 65 y más años $(\chi 23=29,732 \mathrm{p}=.000)$, es decir, los varones son los que hablan "algo más" de política con sus amigos, mientras que las mujeres, mayoritariamente, nunca hablan de este tema. Al considerar la variable sexo como moderadora, obtenemos un efecto significativo para los varones $(\chi 23=15,123 \mathrm{p}=.002)$ y mujeres de la generación del desarrollo $(\chi 23=23,062 \mathrm{p}=.000)$, es decir, tanto los varones como las mujeres de 55 a 64 años hablan en mayor medida de política con sus amigos que sus congéneres del grupo de edad de 65 y más años. Se refleja el efecto generacional entre la generación del desarrollo y de la guerra civil y, a su vez, el efecto de género dentro de cada generación, aunque éste se deja sentir, en mayor medida, en el grupo de mayor edad.

El tabú existente sobre la política, durante los casi cuarenta años del franquismo, ha calado fuerte en las personas mayores educadas bajo la represión política durante la mayor parte de su vida, y eso es lo que les impediría hablar abiertamente de esos temas con amigos, por el miedo interiorizado a las posibles represalias. Los menores de esa edad (de 55 a 64 años) han vivido ya un largo periodo democrático, lo que les habría permitido superar los miedos y sustituirlos por los valores de la libertad de opinión y de expresión.

Hablar de política con los familiares. En esta dimensión aparece una diferencia generacional entre los jóvenes y los adultos, ya que los jóvenes rara vez o nunca hablan sobre este tema con sus familiares $(52,8 \%)$, en contraste con los adultos que indican que las conversaciones sobre este tema son algo más frecuentes (50,7\%); mientras los adultos mayores, coincidiendo con los jóvenes, mencionan con mayor frecuencia que rara vez o nunca hablan con sus familiares de política (62\%).

$\mathrm{El}$ análisis de los grupos de edad de nuestro interés evidencia nuevamente diferencias significativas en la misma línea del patrón anteriormente indicado, es decir, la mayoría de personas de 55 a 64 años hablan con regularidad sobre política con sus familiares, mientras que las personas de 65 años y más nunca lo hacen. Los datos ponen de manifiesto que el efecto generacional está de nuevo presente para esta dimensión (Tabla 4). 
El estudio de esta dimensión en relación con el sexo culmina con la presencia del efecto generacional, aunque sólo con significación estadística para el caso de las mujeres; en concreto, las mujeres de 65 años y más son las que menos hablan de política con sus familiares respecto de sus pares de 55 a 64 años $(\chi 23=15,455 \mathrm{p}=.001)$; lo mismo ocurre cuando se realiza el análisis intergrupo, es decir, las mujeres de 65 y más años hablan menos de política con sus familiares que los hombres de la misma edad $(\chi 23=16,644$ $\mathrm{p}=.001)$.

El efecto generacional y de género se hace presente sólo para el grupo de mujeres de 65 y más años. Aparece de nuevo el gender gap para las mujeres de la generación de la guerra civil, socializadas en un déficit democrático y con unos estereotipos de género que profundizan en una subcultura tradicional "femenina" que las inhibe en mayor medida que a los hombres de los temas políticos.

\section{Tabla 4}

Frecuencia con la que se habla de política con los familiares según grupos etarios y sexo

Frecuencia con la que se habla de política con los familiares $(\%)$

\begin{tabular}{|c|c|c|c|c|c|c|c|}
\hline $\begin{array}{l}\text { Orientación } \\
\text { del contraste }\end{array}$ & $\begin{array}{l}\text { Categorías } \\
\text { de Control }\end{array}$ & $\begin{array}{c}\text { Grupo de } \\
\text { Comparación }\end{array}$ & $\begin{array}{c}\text { A } \\
\text { menudo }\end{array}$ & $\begin{array}{c}\text { Algunas } \\
\text { veces }\end{array}$ & Raramente & Nunca & $\begin{array}{c}\text { TOTAL } \\
(\mathrm{N})\end{array}$ \\
\hline \multirow{4}{*}{$\begin{array}{l}\text { Sexo / } \\
\text { Edad }\end{array}$} & \multirow{2}{*}{ Hombres } & 55 a 64 & 12,6 & 34,0 & 31,4 & 22,0 & 159 \\
\hline & & 65 y más & 12,6 & 26,6 & 31,8 & 29,0 & 214 \\
\hline & \multirow{2}{*}{ Mujeres** } & 55 a 64 & $18,2 *$ & 25,5 & 24,8 & $31,5 *$ & 165 \\
\hline & & 65 y más & $8,4 *$ & 20,6 & 24,1 & $46,9 *$ & 286 \\
\hline \multirow{4}{*}{$\begin{array}{l}\text { Edad / } \\
\text { Sexo }\end{array}$} & \multirow{2}{*}{55 а $64 * *$} & Hombres & 12,6 & 34,0 & 31,4 & $22,0 *$ & 159 \\
\hline & & Mujeres & 18,2 & 25,5 & 24,8 & $31,5 *$ & 165 \\
\hline & \multirow{2}{*}{65 y más** } & Hombres & 12,6 & 26,6 & 31,8* & 29,0* & 214 \\
\hline & & Mujeres & 8,4 & 20,6 & $24,1 *$ & $46,9 *$ & 286 \\
\hline
\end{tabular}

*Residuos estandarizados corregidos mayor en valor absoluto a 1,96. / ** Significancia estadística al 0,05. 


\section{Emilia Riesco - Género, Generación e Implicación Política}

En el análisis de la pregunta "estoy mejor informado sobre política que la mayoría de la gente" (CIS, estudio 2807, p. 26), se observa una tendencia similar en las categorías de edad extremas. Los "adultos mayores y ancianos" $(21,8 \%)$ y los "jóvenes y adultos jóvenes” (19,1\%) presentan las menores proporciones de sujetos que consideran estar mejor informados en política. Por el contrario, en los "adultos" (35 a 54 años) existe una mayor proporción de personas que manifiestan estar mejor informadas que el resto $(23,6 \%)$.

Considerando la variable sexo como moderadora, observamos que los varones se sienten mejor informados $(29,1 \%)$ que las mujeres $(15,5 \%)$. Sólo se dan diferencias significativas para las mujeres de ambos grupos etarios $(\chi 23=13,660 \mathrm{p}=.003) \mathrm{y}$, dentro de estas, las mujeres mayores de 65 años son las que afirman estar peor informadas que sus pares femeninas de 55 a 64 años (Tabla 5).

Tabla 5

Información sobre política según grupos etarios y sexo

Estoy mejor informado sobre política que la mayoría de la gente $(\%)$

\begin{tabular}{|c|c|c|c|c|c|c|c|}
\hline \multirow[b]{2}{*}{$\begin{array}{c}\text { Orientación } \\
\text { del } \\
\text { contraste }\end{array}$} & \multirow[b]{2}{*}{$\begin{array}{c}\text { Categorías de } \\
\text { Control }\end{array}$} & \multirow[b]{2}{*}{$\begin{array}{l}\text { Grupo de } \\
\text { Comparación }\end{array}$} & & & & & \\
\hline & & & $\begin{array}{l}\text { Muy de } \\
\text { acuerdo }\end{array}$ & $\begin{array}{c}\text { De } \\
\text { acuerdo }\end{array}$ & $\begin{array}{c}\text { En } \\
\text { desacuerdo }\end{array}$ & $\begin{array}{c}\text { Muy en } \\
\text { desacuerdo }\end{array}$ & $\begin{array}{l}\text { TOTAL } \\
(\mathrm{N})\end{array}$ \\
\hline \multirow{4}{*}{$\begin{array}{l}\text { Sexo / } \\
\text { Edad }\end{array}$} & \multirow{2}{*}{ Hombres** } & 55 a 64 & 5,7 & $28,3^{*}$ & $44,8^{*}$ & 21,1 & 279 \\
\hline & & 65 y más & 4,9 & $19,4^{*}$ & $53,8 *$ & 21,9 & 288 \\
\hline & \multirow{2}{*}{ Mujeres** } & 55 a 64 & 3,4 & 13,3 & $48,5^{*}$ & $34,8 *$ & 233 \\
\hline & & 65 y más & 1,3 & 13,5 & $37,3^{*}$ & $48,0 *$ & 394 \\
\hline \multirow{4}{*}{$\begin{array}{l}\text { Edad / } \\
\text { Sexo }\end{array}$} & \multirow{2}{*}{55 a $64 * *$} & Hombres & 5,7 & $28,3 *$ & 44,8 & $21,1 *$ & 279 \\
\hline & & Mujeres & 3,4 & $13,3 *$ & 48,5 & $34,8 *$ & 233 \\
\hline & \multirow{2}{*}{65 y más** } & Hombres & $4,9 *$ & $19,4^{*}$ & $53,8 *$ & $21,9 *$ & 288 \\
\hline & & Mujeres & $1,3^{*}$ & $13,5^{*}$ & $37,3 *$ & $48,0 *$ & 394 \\
\hline
\end{tabular}

* Residuos estandarizados corregidos mayor en valor absoluto a 1,96. / ** Significancia estadística al 0,05 
Al considerar el grupo de edad como variable moderadora, también aparecen diferencias significativas, tanto para el grupo de edad de 55 a 64 años $(\chi 23=23,733 \mathrm{p}=.000)$, como para el grupo de 65 años y más $(\chi 23=52,347 \mathrm{p}=.000) \mathrm{y}$, en este caso, al igual que en el análisis anterior, las mujeres de ambos grupos de edad son las que afirman que no están bien informadas de política en comparación con los varones de sus respectivos grupos de edad.

Los datos empíricos nos llevan a constatar que, al igual que en otros países desarrollados, hay diferencias significativas por sexo, mostrando las mujeres menor grado de información política.

Tiempo dedicado a informarse. Otro factor revelador del interés por la política es el tiempo que dedican a informarse de la actualidad política, medido, concretamente, por el tiempo que suelen pasar viendo o escuchando informativos en televisión o radio, así como el seguimiento que hacen a través de la prensa escrita o Internet.

Del análisis de contingencia realizado (CIS, estudio 2807, p. 28, 28a, 29, 29a, 30, 31, 32, 33) a partir de la frecuencia acumulada de los tres medios de información más utilizados (TV, prensa y radio) y circunscrito a los grupos de edad objeto de estudio, observamos que la tendencia de ambos grupos es bastante homogénea. Así, uno de cada tres entrevistados, de ambos grupos de edad, utiliza estos medios para informarse frecuentemente de la actualidad política. Sin embargo, la mayoría de cada grupo asegura que no utiliza nunca dichos medios y, en términos comparativos, los de 65 y más años son los que menos los utilizan.

El uso del periódico como medio de información política. El análisis del uso del periódico muestra que, al igual que en la distribución de los medios en general, la mayoría de los entrevistados no utiliza nunca este medio para informarse. Una situación que, analizada desde los distintos grupos de edad, se reafirma para los grupos extremos, es decir, los más jóvenes y los más viejos son los que mayoritariamente nunca utilizan este medio para informarse. Esta tendencia se invierte para los grupos de mediana edad. Esta situación se confirma y reafirma al constatar que las personas de 55 a 64 años utilizan más el periódico que los de 65 y más años.

A la luz de los datos, parece existir una cierta relación entre la edad del entrevistado y el uso de este medio para informarse, sin embargo, es una 


\section{Emilia Riesco - Género, Generación e Implicación Política}

distribución no lineal, alcanzando el mayor uso del periódico en la edad mediana.

El análisis de la utilización del periódico por parte de los grupos de edad objeto de estudio, controlado por el sexo, nos indica que los hombres de ambos grupos de edad lo utilizan más que las mujeres. Esta situación de menor acceso informativo de la mujer se ve reafirmada cuando hacemos la comparación intergrupo de edad, ya que las mujeres de 65 y más años leen menos periódicos que las mujeres de 55 a 64 años, siendo estas diferencias estadísticamente significativas. Por tanto, el acceso a la información de los periódicos se ve limitado por factores de género en detrimento de la mujer y, aún más, cuando estas son de edad avanzada, siendo estas diferencias significativas tanto para el grupo de 55 a 64 años $(\chi 25=27,375 \mathrm{p}=.000)$ como para los mayores de 65 años $(\chi 25=38,308 \mathrm{p}=.000)$.

Los datos empíricos nuevamente ponen de manifiesto las diferencias existentes en nuestro país entre hombres y mujeres de las edades consideradas. En este caso, se observa que el gap sexual es evidente. Además, al efecto de género se suma el efecto generación, las mujeres de mayor edad lo utilizan en menor medida todavía.

El análisis del uso de la TV y la radio para informarse de la actualidad política nos revela que se mantiene el mismo patrón que para la prensa escrita.

El uso de Internet como medio de información sobre temas políticos. El uso de Internet como fuente de información política está condicionado, por un lado, por el nivel de recursos con los que cuenta una persona, ya que estos condicionan el acceso a la red y, por otro lado, por el uso político que de Internet hagan los usuarios. El análisis aquí realizado sobre el uso de Internet como medio de información política revela grandes diferencias en función de la edad. El uso de Internet, a nivel general, es del 7,2\%, y donde se concentran los mayores valores es en los grupos de menor edad, siendo del 3,7\% para los de 55 a 64 años y del 2,3\% para los mayores de 65 años.

$\mathrm{El}$ análisis del uso de Internet, respecto al género, nos señala que dentro del grupo de 65 y más años las mujeres son las que menos utilizan Internet para informarse del acontecer político, encontrándose diferencias significativas (Tabla 6) $(\chi 21=5,841 \mathrm{p}=.016)$. Asimismo, se observa que las mujeres mayores de 65 años utilizan menos Internet que sus pares de sexo de 55 a 64 años, siendo también estas diferencias significativas $(\chi 21=6,323$ 
$\mathrm{p}=.012$ ). Es fácil descubrir cómo el factor generacional y de género define una posición desfavorable para las mujeres del grupo de mayor edad. Sin embargo, se observa, con significación estadística, que para el grupo de 55 a 64 años esta tendencia se invierte, y son las mujeres de esta edad las que utilizan más Internet que sus pares masculinos. Consideramos que al ser Internet un medio de información minoritario, posiblemente, las mujeres de 55 a 64 años usuarias de este medio son las que tienen una vida laboral activa y logran borrar la brecha del género en el interés por la política y el uso de Internet o incluso superarla.

Tabla 6

Utilización de Internet como medio de información según grupos etarios y sexo

Utilización de Internet como medio de información (\%)

\begin{tabular}{|c|c|c|c|c|c|}
\hline $\begin{array}{l}\text { Orientación } \\
\text { del contraste }\end{array}$ & $\begin{array}{c}\text { Categorías de } \\
\text { Control }\end{array}$ & $\begin{array}{c}\text { Grupo de } \\
\text { Comparación }\end{array}$ & Sí & No & TOTAL $(\mathrm{N})$ \\
\hline \multirow{4}{*}{ Sexo / Edad } & \multirow{2}{*}{ Hombres** } & 55 a 64 & 3,4 & 96,6 & 326 \\
\hline & & 65 y más & $3,8^{*}$ & $96,2 *$ & 317 \\
\hline & \multirow{2}{*}{ Mujeres** } & 55 a 64 & 4,1 & 95,9 & 245 \\
\hline & & 65 y más & $1,1^{*}$ & 98,9* & 438 \\
\hline \multirow{4}{*}{ Edad / Sexo } & \multirow{2}{*}{55 a $64 * *$} & Hombres & 3,4 & 96,6 & 326 \\
\hline & & Mujeres & $4,1^{*}$ & 95,9* & 245 \\
\hline & \multirow{2}{*}{65 y más** } & Hombres & 3,8 & 96,2 & 317 \\
\hline & & Mujeres & $1,1^{*}$ & 98,9* & 438 \\
\hline
\end{tabular}

* Residuos estandarizados corregidos mayor en valor absoluto a 1,96. / ** Significancia estadística al 0,05

En resumen, la proporción de personas que utilizan los medios de comunicación para informarse sobre política es baja y más en el caso de los grupos de edad estudiados; dentro de estos grupos se constata la tendencia de que las personas de 65 y más años hacen un menor uso de ellos que las de 55 a 64 años. Aparecen diferencias de género dentro de un mismo grupo de edad, siendo las mujeres las que se informan menos de política, situación que se potencia con la edad, como se observa cuando se compara a las 


\section{Emilia Riesco - Género, Generación e Implicación Política}

mujeres de ambos grupos. Sin embargo, para las mujeres de la generación del desarrollo, se invierte la tendencia en el uso de Internet y son ellas las que utilizan más la red para informarse de temas políticos que sus coetáneos varones, siempre teniendo en cuenta que es minoritario el uso que se hace de este medio.

\section{Participación Electoral}

Las elecciones competitivas constituyen la pieza central del sistema democrático. Aquí abordamos el análisis de la participación electoral de los grupos etarios estudiados a través de varios indicadores, tales como el ejercicio del sufragio, el sentido del mismo y la orientación del voto.

\section{Ejercicio del sufragio.}

Ejercicio del sufragio en las Elecciones Generales del año 2004. El análisis de los datos de las elecciones generales del año 2004 (CIS, estudio 2559) nos indica que a mayor edad mayor es la participación electoral, ya que más del $90 \%$ de los adultos de 45 y más años participó en estas elecciones ejerciendo su voto, mientras que la participación de los más jóvenes alcanzó un promedio de $81 \%$.

Considerando la interacción entre los grupos de edad y el sexo, el análisis nos indica que sólo existen diferencias significativas, explicadas por el sexo, en el grupo de 65 y más años $(\chi 22=13,602 \mathrm{p}=.001)$ (Tabla 7), de tal modo que los varones de 65 años y más fueron a votar en mayor proporción que las mujeres, con una participación del $94,6 \%$ y $89 \%$ respectivamente. Se aprecia la influencia de la generación en las mujeres del grupo de 65 y más años que, durante gran parte de su vida, se han visto relegadas a la esfera de lo privado, quedando lo público como algo privativo de los varones.

Ejercicio del sufragio en las Elecciones Generales del año 2008. El análisis del sufragio en estos comicios (CIS, estudio 2757) muestra bastantes similitudes con lo acontecido en el año 2004. Se repite que a mayor edad, mayor es la participación electoral. El análisis comparativo de la participación en estas elecciones muestra diferencias significativas para los grupos de edad estudiados, siendo las personas de 55 a 64 años las que votaron en mayor medida que el grupo de edad de 65 años y más. 
El análisis de la interacción entre el sexo y el ejercicio del voto indica que las diferencias significativas encontradas son generacionales $(\chi 22=6,725$ $\mathrm{p}=.035)$ y de sexo $(\chi 22=10,302 \mathrm{p}=.006)$. De esta forma, las mujeres de $65 \mathrm{y}$ más años son las que menos ejercen el voto, en comparación con sus pares femeninas de 55 a 64 años y con los varones del mismo grupo de edad (Tabla 8).

Tabla 7

Ejercicio del sufragio en el año 2004, sexo y grupos etarios y sexo

Ejercicio del sufragio en el año 2004

\begin{tabular}{|c|c|c|c|c|c|c|}
\hline \multicolumn{3}{|c|}{ Grupo Etario y sexo* } & $\begin{array}{c}\text { Fue a votar } \\
\text { y votó }\end{array}$ & $\begin{array}{c}\text { Fue a votar, pero } \\
\text { no pudo hacerlo }\end{array}$ & $\begin{array}{l}\text { Prefirió } \\
\text { no votar }\end{array}$ & TOTAL \\
\hline \multirow{8}{*}{$\begin{array}{l}55 \text { a } 64 \\
\text { años }\end{array}$} & \multirow[t]{3}{*}{ Hombre } & $\mathrm{N}$ & 286 & 4 & 17 & 307 \\
\hline & & $\%$ & $93,2 \%$ & $1,3 \%$ & $5,5 \%$ & $100 \%$ \\
\hline & & R. C. & 0,5 & $-1,2$ & 0,2 & \\
\hline & \multirow[t]{3}{*}{ Mujer } & $\mathrm{N}$ & 320 & 9 & 18 & 347 \\
\hline & & $\%$ & $92,2 \%$ & $2,6 \%$ & $5,2 \%$ & $100 \%$ \\
\hline & & R. C. & $-0,5$ & 1,2 & $-0,2$ & \\
\hline & \multirow[t]{2}{*}{ Total } & $\mathrm{N}$ & 606 & 13 & 35 & 654 \\
\hline & & $\%$ & $92,7 \%$ & $2,0 \%$ & $5,4 \%$ & $100 \%$ \\
\hline \multirow{8}{*}{$\begin{array}{l}65 \text { años } \\
\text { y más }\end{array}$} & \multirow[t]{3}{*}{ Hombre } & $\mathrm{N}$ & 456 & 6 & 20 & 482 \\
\hline & & $\%$ & $94,6 \%$ & $1,2 \%$ & $4,1 \%$ & $100 \%$ \\
\hline & & R. C. & 3,4 & $-3,2$ & $-1,7$ & \\
\hline & \multirow[t]{3}{*}{ Mujer } & $\mathrm{N}$ & 596 & 31 & 43 & 670 \\
\hline & & $\%$ & $89,0 \%$ & $4,6 \%$ & $6,4 \%$ & $100 \%$ \\
\hline & & R. C. & $-3,4$ & 3,2 & 1,7 & \\
\hline & \multirow[t]{2}{*}{$\overline{\text { Total }}$} & $\mathrm{N}$ & 1052 & 37 & 63 & 1152 \\
\hline & & $\%$ & $91,3 \%$ & $3,2 \%$ & $5,5 \%$ & $100 \%$ \\
\hline
\end{tabular}

* Significancia estadística al 0,05.

Participación electoral en las Elecciones al Parlamento Europeo del año 2009. Se ha realizado el análisis de la participación electoral en estas elecciones (CIS, estudio 2807) para ver si se mantiene la misma tendencia de participación que en las elecciones al Parlamento Español o si, por el 


\section{Emilia Riesco - Género, Generación e Implicación Política}

contrario, la menor cercanía a la institución europea actúa como elemento disuasorio. El análisis nos indica que, al igual que en los sufragios anteriormente analizados, los mayores presentan, en términos absolutos y comparados, una mayor participación en las elecciones. Sin embargo, es preciso señalar que, en términos globales, la participación electoral en las elecciones al Parlamento Europeo es mucho menor que en las elecciones generales, tanto del 2004 como del 2008. Por ese motivo, la participación de los más viejos alcanza sólo un $75 \%$, pero es ciertamente mayor que la del total de la población, que fue de un $65,5 \%$.

Tabla 8

Ejercicio del sufragio en el año 2008 según grupos etarios y sexo

Ejercicio del sufragio en el año $2008(\%)$

\begin{tabular}{|c|c|c|c|c|c|c|}
\hline $\begin{array}{l}\text { Orientación } \\
\text { del contraste }\end{array}$ & $\begin{array}{l}\text { Categorías de } \\
\text { Control }\end{array}$ & $\begin{array}{c}\text { Grupo de } \\
\text { Comparación }\end{array}$ & $\begin{array}{l}\text { No pude } \\
\text { votar }\end{array}$ & $\begin{array}{l}\text { Normalmente } \\
\text { voto, pero no } \\
\text { quise ir a votar }\end{array}$ & Sí vote & Total \\
\hline \multirow{4}{*}{$\begin{array}{l}\text { Sexo / } \\
\text { Edad }\end{array}$} & \multirow{2}{*}{ Hombres } & 55 a 64 & 0,8 & 5,6 & 93,6 & 375 \\
\hline & & 65 y más & 2,1 & 6,4 & 91,5 & 528 \\
\hline & \multirow{2}{*}{ Mujeres** } & 55 a 64 & $2,4^{*}$ & 5,7 & 91,9 & 418 \\
\hline & & 65 y más & $5,7 *$ & 5,4 & 88,9 & 714 \\
\hline \multirow{4}{*}{$\begin{array}{l}\text { Edad / } \\
\text { Sexo }\end{array}$} & \multirow{2}{*}{55 a 64} & Hombres & 0,8 & 5,6 & 93,6 & 375 \\
\hline & & Mujeres & 2,4 & 5,7 & 91,9 & 418 \\
\hline & \multirow{2}{*}{65 y más** } & Hombres & $2,1^{*}$ & 6,4 & 91,5 & 528 \\
\hline & & Mujeres & $5,7 *$ & 5,4 & 88,9 & 740 \\
\hline
\end{tabular}

*Residuos estandarizados corregidos mayor en valor absoluto a 1,96. / ** Significancia estadística al 0,05

El análisis de la participación según el sexo nos muestra efectos generacionales y de género. De esta forma, se observa que los varones de 65 y más años muestran mayor disposición a participar en las votaciones que sus pares de 55 a 64 años $(\chi 22=8,785$ p=.012) (Tabla 9). Respecto al efecto 
de género, observamos que los hombres de 55 a 64 años son los que más participaron respecto de sus pares femeninos $(\chi 22=10,213 \mathrm{p}=.006)$.

Tabla 9

Ejercicio del sufragio en el año 2009 según grupos etarios y sexo

Ejercicio del sufragio en el año $2009(\%)$

\begin{tabular}{|c|c|c|c|c|c|c|}
\hline $\begin{array}{l}\text { Orientación } \\
\text { del contraste }\end{array}$ & $\begin{array}{l}\text { Categorías de } \\
\text { Control }\end{array}$ & $\begin{array}{c}\text { Grupo de } \\
\text { Comparación }\end{array}$ & $\begin{array}{l}\text { No pude } \\
\text { votar }\end{array}$ & $\begin{array}{l}\text { Normalmente } \\
\text { voto, pero no } \\
\text { quise ir a votar }\end{array}$ & Sí vote & Total \\
\hline \multirow{4}{*}{$\begin{array}{l}\text { Sexo / } \\
\text { Edad }\end{array}$} & \multirow{2}{*}{ Hombres** } & 55 a 64 & 3,8 & $21,0 *$ & 75,2 & 319 \\
\hline & & 65 y más & 7,0 & $13,4 *$ & 79,6 & 313 \\
\hline & \multirow{2}{*}{ Mujeres } & 55 a 64 & 10,2 & 16,8 & 73,0 & 244 \\
\hline & & 65 y más & 9,1 & 15,5 & 75,4 & 439 \\
\hline \multirow{4}{*}{$\begin{array}{l}\text { Edad / } \\
\text { Sexo }\end{array}$} & \multirow{2}{*}{55 a $64 * *$} & Hombres & $3,8^{*}$ & 21,0 & 75,2 & 319 \\
\hline & & Mujeres & $10,2 *$ & 16,8 & 73,0 & 244 \\
\hline & \multirow{2}{*}{65 y más } & Hombres & 7,0 & 13,4 & 79,6 & 313 \\
\hline & & Mujeres & 9,1 & 15,5 & 75,4 & 439 \\
\hline
\end{tabular}

*Residuos estandarizados corregidos mayor en valor absoluto a 1,96. / ** Significancia estadística al 0,05

Consideración del voto: ¿derecho o deber? Según el análisis de los datos del estudio postelectoral del CIS al Parlamento Europeo del 2009 (estudio 2807, p. 27), los ciudadanos de 65 y más años son los que en mayor medida interpretan el voto como un deber frente al resto de categorías de edad. Así, para el 47,5\% es un deber frente al 52,5\% que lo entienden como un derecho. En términos generales, los encuestados en este estudio consideran el hecho de votar más como un derecho $(66,3 \%)$ que como un deber $(33,7 \%)$. Sin embargo, conforme aumenta la edad de los entrevistados, la tendencia a considerar el voto como un deber aumenta considerablemente y resulta significativo en términos comparados. Tal es el caso de los sujetos con edades entre 55 a 64 años y de 65 y más años, donde, si bien la mayoría consideran el voto como un derecho, también es cierto que, en términos 


\section{Emilia Riesco - Género, Generación e Implicación Política}

comparativos con el resto de grupos etarios, estos grupos se componen de una proporción relevante y significativa de sujetos que consideran el voto como un deber. En el grupo de 55 a 64 años, seis de cada diez consideran que es un derecho, consideración todavía alejada de la que tienen las cohortes más jóvenes, nacidas y socializadas en la democracia; tres cuartas partes de los jóvenes de 18 a 24 años consideran que el ejercicio del voto es un derecho.

El análisis según el sexo nos muestra que los hombres de 55 a 64 años, respecto a los de 65 años y más, consideran el ejercicio electoral más como derecho que como deber $(\chi 21=9,333 \mathrm{p}=.002)$ (Tabla 10). Las comparaciones adquieren dimensión de género entre 55 a 64 años, al ser los varones los que, de forma estadísticamente significativa, identifican la participación electoral con un derecho $(\chi 21=5,882 \mathrm{p}=.015)$ (Tabla 10). Las mujeres de esa edad han tenido un acceso reducido al mercado laboral y han sido socializadas con roles de género diferenciados que limitan su participación en la política y, por ello, la actitud y consideración hacia la misma.

Tabla 10

Consideración del voto como derecho o como deber según grupos etarios y sexo

Consideración del voto como derecho o como deber $(\%)$

\begin{tabular}{|c|c|c|c|c|c|}
\hline $\begin{array}{l}\text { Orientación del } \\
\text { contraste }\end{array}$ & $\begin{array}{l}\text { Categorías de } \\
\text { Control }\end{array}$ & $\begin{array}{c}\text { Grupo de } \\
\text { Comparación }\end{array}$ & Un derecho & Un deber & Total \\
\hline \multirow{4}{*}{ Sexo / Edad } & \multirow{2}{*}{ Hombres** } & 55 a 64 & $64,2 *$ & 35,8* & 307 \\
\hline & & 65 y más & $52,0 *$ & $48,0 *$ & 304 \\
\hline & \multirow{2}{*}{ Mujeres } & 55 a 64 & 53,8 & 46,2 & 234 \\
\hline & & 65 y más & 52,9 & 47,1 & 401 \\
\hline \multirow{4}{*}{ Edad / Sexo } & \multirow{2}{*}{55 a $64 * *$} & Hombres & $64,2 *$ & $35,8 *$ & 307 \\
\hline & & Mujeres & $53,8 *$ & $46,2 *$ & 234 \\
\hline & \multirow{2}{*}{65 y más } & Hombres & 52,0 & 48,0 & 304 \\
\hline & & Mujeres & 52,9 & 47,1 & 401 \\
\hline
\end{tabular}

*Residuos estandarizados corregidos mayor en valor absoluto a 1,96. / ** Significancia estadística al 0,05. 
En resumen, el ejercicio del sufragio es mayor a medida que aumenta la edad. Las mujeres tienen menor participación electoral que los varones, y más aún las mujeres mayores de 65 años. La elevada participación de las personas mayores podría estar relacionada con la alta proporción de las mismas que considera el voto más como un deber que como un derecho. Respecto al sexo, observamos que los varones de 65 y más años tienden a considerar el voto más como un deber que como un derecho. En cambio en los hombres de 55 a 64 años ocurre lo contrario. Estos datos ponen de manifiesto que, para los varones de la generación del desarrollo, se ha producido un cambio importante en la asimilación de los derechos cívicos que supone una renovación generacional con cambios de envergadura. No obstante, todavía permanecen algunas diferencias de género. Así, en el caso de las mujeres no se observa ese cambio de consideración.

Orientación del voto. Realizamos el análisis de las preferencias partidistas y de la orientación del voto de los españoles de mayor edad. Aquí presentamos el análisis de las tablas de contingencia de las dos últimas consultas electorales realizadas al Parlamento Español (2008 y 2011), y se comparan los resultados con los obtenidos en el análisis realizado de las elecciones generales del año 2004 y al Parlamento Europeo del 2009 (que no se adjuntan por razones de extensión). La selección de estas elecciones obedece a varias razones. La primera es que ambas son elecciones generales; la segunda que son las más próximas en el tiempo, y la tercera es que en las elecciones de 2008, ya instalados en la crisis, se le renovó la confianza al partido que estaba en el gobierno (PSOE) mientras que en las de 2011 se produjo la victoria del PP que estaba en la oposición.

Orientación del voto en Elecciones Generales del año 2008. El análisis de la orientación del voto en estas elecciones (CIS, estudio 2757) presenta muchas similitudes con los resultados de las elecciones del 2004. La participación general fue del $74 \%$ y da como resultado el triunfo del partido que está en el gobierno, el PSOE. Sin embargo, por primera vez en tres décadas, ambos partidos, PSOE y PP, obtienen más votos que en 2004. El PSOE logró más de once millones de votos y el $48 \%$ de los escaños, el PP logró superar los diez millones de votos y un $44 \%$ de los escaños; son los mejores resultados obtenidos en todo el periodo democrático tanto para el partido vencedor como para el partido perdedor; este doble crecimiento se da 


\section{Emilia Riesco - Género, Generación e Implicación Política}

por la mayor concentración del voto en los dos partidos mayoritarios. Esta misma concentración general del voto se repite para las persona mayores.

Centrándonos en los grupos de población objeto de estudio, el análisis de la dirección del voto nos muestra que ambos grupo de edad votaron principalmente al PSOE y las diferencias significativas se observan exclusivamente en el voto hacia Izquierda Unida (IU) $(\chi 23=11,442 \mathrm{p}=.010)$. Así, observamos que las personas de 55 a 64 años votan más a IU que los mayores de 65 años (Tabla 11). Asimismo, si analizamos los datos en función del tipo de partido, obtenemos una vez más que los adultos mayores y ancianos votan más al PSOE, pero también son los que votan mayoritariamente más al PP, como constata la distribución de votos hacia este partido.

Tabla 11

Partido político al que votó en las elecciones de 2008 según grupos etarios y sexo

Partido político al que votó en 2008 (\%)

\begin{tabular}{|c|c|c|c|c|c|c|c|}
\hline $\begin{array}{l}\text { Orientación } \\
\text { del contraste }\end{array}$ & $\begin{array}{c}\text { Categorías de } \\
\text { Control }\end{array}$ & $\begin{array}{c}\text { Grupo de } \\
\text { Comparación }\end{array}$ & PSOE & PP & IU & $\begin{array}{c}\text { Otro } \\
\text { partido }\end{array}$ & $\begin{array}{l}\text { TOTAL } \\
(\mathrm{N})\end{array}$ \\
\hline \multirow{2}{*}{\multicolumn{2}{|c|}{$\operatorname{Edad}^{* *}$}} & 55 a 64 & 56,0 & 31,1 & $4,6^{*}$ & 8,3 & 627 \\
\hline & & 65 y más & 55,4 & 35,6 & $2,0 *$ & 7,0 & 908 \\
\hline \multirow{4}{*}{$\begin{array}{l}\text { Sexo / } \\
\text { Edad }\end{array}$} & \multirow{2}{*}{ Hombres } & 55 a 64 & 57,4 & 29,8 & 4,9 & 7,9 & 305 \\
\hline & & 65 y más & 53,8 & 35,5 & 3,1 & 7,6 & 383 \\
\hline & \multirow{2}{*}{ Mujeres** } & 55 a 64 & 54,8 & 32,1 & $4,4^{*}$ & 8,7 & 321 \\
\hline & & 65 y más & 56,5 & 35,7 & $1,1 *$ & 6,7 & 524 \\
\hline
\end{tabular}

*Residuos estandarizados corregidos mayor en valor absoluto a 1,96. / ** Significancia estadística al 0,05.

El análisis de la orientación del voto considerando el sexo y los grupos de edad, no arroja diferencias significativas relevantes para la distribución de los votos hacia los partidos mayoritarios. Solamente se observa un efecto significativo generacional en el caso de las mujeres de 65 y más años que tienden a votar menos a IU que sus congéneres de 55 a 64 años $(\chi 23=10,665$ 
$\mathrm{p}=.014)$. No encontramos efectos significativos para el sexo dentro de los grupos de edad (Tabla 12).

El análisis de la orientación del voto en las elecciones de 2008 presenta las mismas pautas que en las elecciones de 2004. En general, se produce una concentración del voto en los dos grandes partidos (tendencia que había caracterizado a España desde los años setenta) y esta tendencia se acentúa más aún en el caso de los de más edad. Las personas de 65 y más años se inclinan por el PP en mayor proporción, superando la media de la población en su conjunto, y menos al resto de partidos. Pese a ello, este grupo mantiene la misma pauta de voto que la sociedad en su conjunto; es decir, ambos grupos de edad votaron principalmente al PSOE (el voto otorgado está por encima de la media del conjunto de la población) y las diferencias significativas sólo se observan en el voto a IU $(\chi 23=11,442 \mathrm{p}=.010)$. Las personas de 55 a 64 años tienden a votar más a este partido que los de 65 años y más. En estas elecciones se produce una elevada concentración del voto en los partidos de izquierdas por el conjunto de la población, posiblemente apelando al voto útil, apareciendo el efecto generación. Así, los de 65 y más años concentran el voto mayoritariamente en el PSOE y los de 55 a 64 lo hacen en mayor proporción en IU.

Orientación del voto en las Elecciones Generales del año 2011. La participación del conjunto del electorado en estas elecciones fue de casi un $72 \%$, dos puntos inferior a las del 2008, y se produce un relevo en el partido que gobierna. El PP obtiene el 44,6\% de los votos y la mayoría absoluta, mientras que el PSOE ve reducidos sus votos al 28,7\%. Otra de las novedades de estos comicios es la pérdida de la hegemonía bipartidista, que se venía reforzando en las dos legislaturas anteriores.

Del análisis realizado de la orientación del voto (CIS, estudio 2920), obtenemos que ambos grupos de edad votaron principalmente al PP al igual que el resto del electorado. Ahora bien, en términos comparados, encontramos que los mayores de 65 años votan más al PP en contraste con los adultos de 55 a 64 años, que votan en mayor medida a IU u otros partidos $(\chi 23=52,109 \mathrm{p}=.000)($ Tabla 12).

$\mathrm{Al}$ analizar la orientación del voto en función del sexo y la generación, observamos que la mayoría de los varones mayores de 65 años votan al PP. Por el contrario, los varones entre 55 a 64 años votan mayoritariamente al PSOE, IU-LV y a otros partidos. La orientación del voto hacia el PSOE se 


\section{Emilia Riesco - Género, Generación e Implicación Política}

da, mayormente, por varones de entre 55 a 64 años (Tabla 12). En el caso del voto de las mujeres se da un patrón similar al de los varones, es decir, las mujeres mayores de 65 años votan más al PP, mientras que en el caso del voto a IU y otros partidos ocurre lo contrario $(\chi 23=30,927 \mathrm{p}=.000)$. No se observa efecto de género, en cambio sí aparece efecto generación; así, los de la generación del desarrollo votan en menor medida al PP y votan mayoritariamente a los partidos con una orientación ideológica de izquierda.

Tabla 12

Partido político al que votó en las elecciones de 2011 según grupos etarios y sexo Partido político al que votó en 2011 (\%)

\begin{tabular}{|c|c|c|c|c|c|c|c|}
\hline $\begin{array}{l}\text { Orientación } \\
\text { del contraste }\end{array}$ & $\begin{array}{c}\text { Categorías de } \\
\text { Control }\end{array}$ & $\begin{array}{c}\text { Grupo de } \\
\text { Comparación }\end{array}$ & PP & PSOE & IU-LV & $\begin{array}{l}\text { Otro } \\
\text { partido }\end{array}$ & $\begin{array}{c}\text { TOTAL } \\
(\mathrm{N})\end{array}$ \\
\hline \multirow{4}{*}{$\begin{array}{l}\text { Sexo / } \\
\text { Edad }\end{array}$} & \multirow{2}{*}{ Hombres** } & 55 a 64 & $41,8^{*}$ & $33,2 *$ & 8,2 & $16,8^{*}$ & 316 \\
\hline & & 65 y más & $56,8 *$ & 29,4 & $3,0 *$ & $10,9 *$ & 405 \\
\hline & \multirow{2}{*}{ Mujeres** } & 55 a 64 & $43,2 *$ & 30,5 & $9,8 *$ & $16,5^{*}$ & 315 \\
\hline & & 65 y más & $55,6^{*}$ & 32,9 & $3,8 *$ & $7,7 *$ & 495 \\
\hline \multirow{4}{*}{$\begin{array}{c}\text { Edad / } \\
\text { Sexo }\end{array}$} & \multirow{2}{*}{55 a 64} & Hombres & 41,8 & 33,2 & 8,2 & 16,8 & 316 \\
\hline & & Mujeres & 56,8 & 29,4 & 3,0 & 10,9 & 405 \\
\hline & \multirow{2}{*}{65 y más } & Hombres & 43,2 & 30,5 & 9,8 & 16,5 & 315 \\
\hline & & Mujeres & 55,6 & 32,9 & 3,8 & 7,7 & 495 \\
\hline
\end{tabular}

*Residuos estandarizados corregidos mayor en valor absoluto a 1,96. / ** Significancia estadística al 0,05.

El análisis comparado de los resultados de las encuestas postelectorales, realizadas por el CIS, de las elecciones generales de los años 2004, 2008, 2011 y de las elecciones al parlamento europeo de 2009, nos indica que se mantiene la tendencia del voto de las personas mayores de 65 años, y que esta tendencia es hacia un voto más conservador que el resto de los votantes, a la vez que se da un mayor apego al partido que en ese momento está en el gobierno. Así, en las elecciones del 2004, que dieron la victoria al PSOE frente al PP, que gobernaba en ese momento, los ciudadanos de 65 años y 
más votaron mayoritariamente al PSOE; sin embargo, lo hicieron en menor medida que el conjunto de la población, con una diferencia de casi seis puntos, la misma diferencia del voto otorgado al PP por parte de los mayores con respecto a la media del conjunto del electorado.

En las elecciones generales de 2008, las personas de 65 y más años mantienen la tendencia de votar al PSOE, pero, en el grupo de 55 a 64 años se observa, significativamente $(\chi 216=16,982 \mathrm{p}=.009)$, que el voto al PSOE aumenta (Tabla 11).

En las elecciones del 2009 al Parlamento Europeo, ya instalados en la crisis económica, el PSOE desciende en voto recibido por el conjunto de la población; sin embargo los mayores apenas le retiran su confianza, otorgándosela más de un punto por encima del conjunto de la población $(50,2 \%$ vs. $48,6 \%)$ y también siguen votando más al PP que el total de la ciudadanía $(40,6 \%$ vs. $37,2 \%)$.

En las elecciones generales del 2011, en las que de nuevo se ha dado la alternancia en el gobierno ganando las elecciones el Partido Popular, se observa el mismo fenómeno aunque con menor intensidad; así, los mayores de 65 años votan al PSOE, partido que está en el gobierno en el momento de las elecciones, por encima de la media del conjunto de los electores $(1,8 \%)$, pero a su vez también votan más al PP (7,8\% más que la media), siendo el valor más elevado del otorgado por el electorado a este partido. Asimismo, estos datos ponen de manifiesto la tendencia, ya indicada, a votar menos a otros partidos, entre ellos a Izquierda Unida-Los Verdes. Sin embargo, se evidencia un cambio de tendencia para las personas de 55 a 64 años; estas personas votan comparativamente más a los partidos de izquierda y menos al PP que la generación que les precede; asimismo, otorgan su voto en mayor medida a los partidos minoritarios, rompiendo con la tendencia a concentrar su voto en los dos grandes partidos. Esta tendencia se evidencia de forma muy clara en las últimas elecciones, aunque ya se dejaba notar en las elecciones anteriores. Otro cambio importante, puesto de manifiesto en estos comicios, es la desaparición del efecto de género para la generación del desarrollo; esta tendencia, ya apuntada en las elecciones generales del 2008, se confirma estadísticamente en el 2011; así, se observa que las mujeres de 55 a 64 años expresan una orientación de voto similar a sus coetáneos varones. Las mujeres de esta edad distan mucho de las mujeres que les preceden ya que, en general, tienen mayores niveles de formación, se han incorporado al mercado de trabajo, han madurado con el uso masivo de las 


\section{Emilia Riesco - Género, Generación e Implicación Política}

nuevas tecnologías, y todos estos factores convergen en una nueva forma de ver el mundo y experimentar el compromiso cívico.

\section{Discusión}

\section{Interés por la Política}

El interés por la política hace referencia a la curiosidad que los ciudadanos manifiestan por los asuntos públicos y que, previsiblemente, les llevará a estar atentos sobre lo que ocurre en el ámbito político; es una de las actitudes que más influye en la participación política, aunque esta influencia no es directa, ni es la misma para todos los tipos de participación (Bonet, Martín y Montero, 2006). El interés por la política, tal como la hemos analizado, tiene como objeto al propio ciudadano y, más concretamente, la percepción que tiene de sí mismo como actor político. Desde la perspectiva clásica de la cultura política, se considera al interés por la política y a la eficacia política interna como los componentes sustanciales de la dimensión conocida como "implicación política" de los ciudadanos (Bonet et al., 2006). La literatura sobre el tema parece coincidir al calificar que la "desafección política" es el rasgo que mejor define a la cultura política española (Montero y Torcal, 1990; Morán y Benedicto, 1995; Orizo, 1996); sin embargo, esa actitud negativa no han sido óbice para dar apoyo al régimen democrático. Nuestros resultados son coincidentes en gran medida con los de otros autores. No obstante, es preciso hacer constar que la principal dificultad que hemos encontrado para contrastar los resultados, en esta dimensión, estriba en la ausencia de estudios con datos homogéneos para algunos de los indicadores que hemos analizado y, en el caso de existir, no han tenido en cuenta las mismas categorías de edad en su análisis.

En España, el nivel de interés por la política, en general, no ha sufrido grandes oscilaciones después de tres décadas de democracia, y está muy por debajo de la media de los países europeos (ESE, 2002; 2009; 2012; Gunther y Montero, 2001; ${ }^{1}$ Gunther, Montero y Torcal, 2001; Torcal, 1995; 2006). Solo un $20 \%$ de los españoles dice tener interés por la política según el estudio realizado por Bonet et al. (2006), un 26\% según los datos de la ESE de 2009 o $28 \%$ de la ESE de 2010-11; los españoles siguen destacando por ser el país con menor interés por la política de toda Europa. Además, al igual que en otros países desarrollados, hay diferencias significativas de género, 
mostrando las mujeres un menor interés (García Escribano y Frutos, 1999; Verba, Nie y Kim, 1978).

Esta falta de interés puede deberse, en gran parte, a la percepción individual de la complejidad de la política. A los españoles en general, la política les resulta compleja en una proporción muy superior que a los ciudadanos del resto de Europa (ESE, 2009) y, en particular, a las personas mayores la política les resulta compleja en mayor medida, datos coincidentes en gran parte con otros estudios (Barrio y Sancho, 2012; Pérez Ortiz, 2009b; 2006; 2005; 2002). Son varias las explicaciones que permiten justificar esto y que han sido planteadas desde los años sesenta. Por una parte, la explicación estructural plantea que el desigual acceso a diversos recursos explica por qué algunas personas son más activas políticamente que otras; así, las personas que disponen de menos recursos socioeconómicos manifiestan un menor interés e implicación política (Verge y Tormos, 2012); esta afirmación es coincidente con los resultados aquí expuestos, lo que explicaría un menor interés e implicación en los asuntos públicos por parte de las mujeres. Por otra parte incide el efecto generacional; las personas mayores de 65 años han sido socializadas en la dictadura, con escasas o nulas posibilidades de participación política y con una clara diferenciación de roles de género, donde la socialización de las mujeres tiende a centrarse en el espacio privado y en roles políticos más pasivos, frente a la socialización de los varones centrada en el espacio público. La educación, tanto en la familia como en la escuela, incidía en esa división de roles que para las mujeres suponía alejarse de la esfera pública, con una exaltación de los valores de esposa y madre, inculcándoles un papel conformista y pasivo (García Escribano y Frutos, 1999).

El consumo de información política es otro indicador del interés por la política. Los resultados de la cuarta ola de la Encuesta Social Europea muestran que en España el consumo de televisión es moderado y que es el preferido frente a la radio y la prensa (alrededor del 38\% de los españoles no escucha nunca la radio y un $45 \%$ nunca lee los periódicos). Del conjunto de los españoles sólo un $18 \%$ ve noticias políticas más de una hora al día. El bajo consumo de información política está relacionado con el bajo interés por la política que existe en España. El porcentaje de personas que se interesan "mucho" o "bastante" por la política es el más bajo de Europa (26\%). En Dinamarca, el $72 \%$ del conjunto de personas se interesan "mucho" o "bastante" por la política, prácticamente igual que el conjunto de 


\section{Emilia Riesco - Género, Generación e Implicación Política}

españoles que se interesan "poco" o "nada" (73\%) (ESE, 2009). Esta falta de interés puede deberse, a su vez, a la percepción individual de la complejidad de la política. Los resultados de nuestro estudio muestran que una de cada tres personas, de los grupos de edad objeto de análisis, afirman que utilizan la televisión, radio y prensa, para informarse frecuentemente de la actualidad política; sin embargo, la mayoría de los entrevistados en cada grupo aseguran que no los utilizan nunca y, de los grupos analizados, los de $65 \mathrm{y}$ más años son los que menos los utilizan. Son coincidentes en revelar que la televisión es el medio más utilizado y que el $50 \%$ y $53 \%$ de las personas que pertenecen a los grupos de edad entre 55 y 64 años y de más de 65 años, respectivamente, utilizan todos o casi todos los días este medio. Asimismo, coinciden en señalar el bajo consumo de radio y prensa. El uso preferente de determinados medios de comunicación para informarse sobre política está en relación con el consumo general que hacen de estos medios; Sánchez Vera y Bódalo (2010) señalan que la televisión es el medio que tiene un mayor número de usuarios de personas mayores, incrementándose su consumo con la edad. Le siguen radio, prensa y, a bastante distancia, Internet.

En España, se observa una brecha informática importante en el uso de las nuevas tecnologías para informarse de política, respecto a la media de los países europeos (ESE, 2009). En el caso concreto del uso de Internet como fuente de información política, según la cuarta ola de la ESE (2008-2009), ${ }^{2}$ sólo un $25 \%$ de los españoles hace uso de este medio todos los días. En países como Suecia, Holanda, Dinamarca o Noruega, entre un 56\% y un $62 \%$ de la población consulta Internet a diario (ESE, 2009). Nuestros resultados son bastante más pesimistas, ya que solo el 7,2\% del conjunto de la población afirma utilizar Internet como medio de información política, concentrándose los valores más altos en los grupos de menor edad, con valores mucho más reducidos para los grupos de edad objeto de nuestro estudio (3,7\% para los de 55 a 64 años y 2,3\% los mayores de 65 años). Esta brecha está doblemente condicionada; por un lado, está determinada por el nivel de recursos con los que cuenta una persona, ya que estos facilitan el acceso a la red y, por otro lado, por el uso político que de Internet hagan los usuarios (Anduiza, Cantijoch y Cristancho, 2010a). Los resultados de nuestro análisis coinciden con la explicación dada por los autores citados. La edad y el género tienen un efecto significativo en el uso de Internet como medio de información política. Los más mayores y las mujeres de más edad consumen menos información política por la red; sin embargo, las mujeres 
de la generación del desarrollo presentan un cambio significativo al ser usuarias más frecuentes que los varones de su generación. En general, la realidad del uso de Internet está muy lejos de la potencialidad que este medio ofrece, ya que, con los datos analizados, podemos afirmar que el seguimiento online de los asuntos públicos es minoritario y sus usuarios tienen un perfil distinto de los que siguen dichos asuntos por los medios tradicionales. Estos resultados coinciden con los expresados por Anduiza et al. (2010a; 2010b), con la excepción del comportamiento señalado de las mujeres de 55 a 64 años, si bien es verdad que en el estudio citado no utilizan esa categoría de edad en su análisis. Castaño, Martín y Martínez (2011) señalan la existencia de un contexto general de desigualdad de género para todas las dimensiones analizadas; así, los hombres aventajan a las mujeres en intensidad del uso, tanto del ordenador como de Internet, en los temas lúdicos y económicos, mientras las mujeres dominan los contenidos de uso más social, como son los relacionados con el empleo, la salud y la formación, dimensión que han denominado "usos de bienestar social", en la que también se incluye la prensa, radio y TV. El estudio de Castaño no diferencia por categorías de edad, por lo que no sabemos si, en el caso de hacerlo, los resultados serían coincidentes con los nuestros, pero pensamos que sí hay una relación directa con el hallazgo de que, precisamente, sean las mujeres comprendidas entre 55 y 64 años las que consuman mayor información política por Internet.

\section{Participación Electoral}

Los hallazgos de nuestra investigación ponen de manifiesto que las personas mayores tienen una tasa de participación electoral más elevada que el conjunto de la sociedad española en todo tipo de comicios, coincidiendo con otros estudios (Pérez Ortiz, 2005; 2009b). Existe una mayor participación en el sufragio a medida que se incrementa la edad de los votantes, alcanzando la máxima participación para el grupo de 55 a 64 años, descendiendo ligeramente para los de 65 y más años. España se sitúa en la franja media europea, con tasas elevadas en participación electoral (Colectivo IOÉ, 2008). Los resultados de nuestro análisis respecto de la orientación del voto de los mayores en las diversas elecciones confirman la tendencia al bipartidismo que ha caracterizado a los resultados electorales en España desde los años 


\section{Emilia Riesco - Género, Generación e Implicación Política}

setenta (Montero y Lago, 2010; Astudillo y Rodon, 2013), y se observa que esa tendencia se acentúa a medida que aumenta la edad (Pérez Ortiz, 2009b).

\section{Comportamiento Electoral de la Generación del Desarrollo}

Los hallazgos de la investigación evidencian un cambio de tendencia en el comportamiento electoral de las personas de la generación del desarrollo con respecto a las personas de mayor edad. Algunos de los cambios más relevantes son los siguientes. En primer lugar, se observa que las personas de 55 a 64 años votan comparativamente más a los partidos de izquierda y a los partidos minoritarios, rompiendo con la tendencia a concentrar su voto en los dos grandes partidos. En segundo lugar, se evidencia un hallazgo importante, la desaparición del efecto de género en las preferencias electorales, tendencia ya apuntada en las elecciones generales del 2008 y confirmada estadísticamente en las elecciones del 2011. Los resultados ponen de manifiesto que la orientación del voto de las mujeres de 55 a 64 años muestra un patrón similar al de los varones de esa cohorte. Estos datos validan nuestra hipótesis de que las nuevas generaciones de mayores mantendrán un comportamiento político que se aleja del que mantienen los viejos actuales. Esto no significa que la generación del desarrollo posea un sistema de valores y actitudes concreto y único sino que, al igual que otros grupos de edad, está integrado por personas dispares, con diferentes niveles socioeconómicos y trayectorias vitales, pero, pese a ello, la influencia "de la generación o cohorte es muy relevante a la hora de establecer el sistema de valores perteneciente a un grupo poblacional" (Barrio y Sancho, 2012, p. 275). En palabras de Gil Calvo (2003, p. 95),

el pertenecer a una u otra generación es algo determinado por la fecha de nacimiento, que ya no se puede cambiar. [...] compartiendo el mismo itinerario biográfico que se vive bajo un común destino histórico. Y como cada generación es distinta a las demás, todas resultan incomparables entre sí, marcando a sus miembros con un cierto determinismo generacional, debido a sus características comunes.

Pues bien, esta generación de nacidos entre 1945 y 1960, que son los que se han jubilado o se jubilarán entre el año 2010 y el 2025, entraron en política a una edad temprana, protagonizaron la Transición Española, 
cuentan con una larga experiencia de compromiso social activo por causas diversas y cabe esperar, como así lo indican los datos analizados, que se prolongue en los años de la ya inmediata jubilación e incluso que se reactive su experiencia activista de los años de juventud. Las investigaciones sobre el cambio de valores tienden a subrayar la importancia de los efectos generacionales; la teoría del postmaterialismo de Inglehart $(1991$; 1998) es un ejemplo de ello.

\section{A Modo de Conclusión}

\section{Generación de la Guerra versus Generación del Desarrollo}

La guerra civil española es el punto de referencia central en las generaciones de personas mayores actuales, actuando como experiencia formativa crucial entre las generaciones de la guerra y anteriores y la generación del desarrollo (Pérez-Díaz, 2003a) imprimiendo claras diferencias entre ellas. Las diferencias en la implicación política son favorables hacia el grupo personas que en la actualidad cuentan con edades comprendidas entre 55 y 64 años, que hemos denominado "generación del desarrollo". Los ciudadanos de esta generación muestran una implicación política más activa que las generaciones que les han precedido.

A pesar de existir diferencias en las actitudes y comportamiento político entre ambas generaciones, las personas que pertenecen a la generación de la guerra sienten como suyas las mismas preocupaciones que el conjunto de la sociedad, no están ensimismadas en sus propios problemas y mantienen un nivel de compromiso cívico, en algunos aspectos, más elevado que el conjunto de la población española, como ocurre con la participación electoral. Pese a considerar la política con un mayor grado de complejidad que los más jóvenes, apenas se sienten peor informados que estos, y esa complejidad no es óbice para que haya una minoría de personas mayores muy interesada por los asuntos públicos y comprometida con ellos. Los mayores coinciden con los más jóvenes en el nivel de información política que poseen. La respuesta dada en los sufragios es solvente y coherente con su orientación ideológica, dejándose sentir el efecto generación.

Sin embargo, para la generación del desarrollo, la política no es más compleja que para las edades inferiores y le dan una importancia similar al conjunto de los ciudadanos. Esta importancia la manifiestan hablando más 


\section{Emilia Riesco - Género, Generación e Implicación Política}

de política con familiares y amigos, así como mostrando una mayor exposición a la información de los medios de comunicación o a través de la red. Las personas de 55 a 64 años consideran el ejercicio del sufragio mayoritariamente como un derecho, frente a los de mayor edad, que lo consideran, en una alta proporción, aunque no mayoritariamente, como un deber; este es un indicador más de la brecha generacional que se establece entre las generaciones de la guerra o anteriores y las generaciones de la democracia, de las cuales ésta es la primera cronológicamente. La generación del desarrollo mantiene una mayor identificación en las actitudes y comportamiento político con el conjunto de la sociedad que con la generación de la guerra, respecto a las dimensiones analizadas.

\section{Género e Implicación Política}

El sexo y la edad son dos variables sociodemográficas clásicas que introducen importantes diferencias tanto en el interés como en la participación política. Respecto del sexo, los hombres han tendido a mostrar mayor interés y a participar tradicionalmente más en los asuntos públicos que las mujeres, pero esas diferencias se han ido reduciendo cada vez más hasta casi desaparecer actualmente, de igual manera que sucede en el caso del voto o la orientación ideológica. Las diferencias de género se evidencian en mayor medida en la generación de la guerra que en la generación del desarrollo. Con el mayor nivel educativo femenino y la lenta pero progresiva incorporación de las mujeres españolas al mundo laboral, las diferencias de género se han ido diluyendo hasta llegar a desaparecer en algunos de los indicadores analizados. Ejemplo de ello es el uso de Internet; las mujeres de la generación del desarrollo invierten la tendencia y son ellas las que utilizan más este medio para informarse sobre temas políticos que sus coetáneos varones. Otro cambio a destacar es la desaparición del efecto de género en la orientación del voto para la generación del desarrollo; esta tendencia, ya apuntada en las elecciones generales del 2008, se confirma estadísticamente en el 2011. Así, se observa que las mujeres de 55 a 64 años expresan una orientación de voto similar a los varones de la misma edad. Estos hallazgos vendrían a validar nuestra hipótesis que señala la importancia del efecto generación en la implicación cívica, coincidiendo con Pérez Ortiz (2005; 2009b), Gil Calvo (2003) y Pérez Díaz (2003b; 2007). 
A la vista de los datos analizados, podríamos afirmar que, con la cohorte que actualmente se encuentra entre los 55 y 64 años de edad, ha llegado la generación que ha superado el síndrome de la dictadura y que está alumbrando un nuevo tipo de ciudadanía con mayor compromiso cívico y que, como es de esperar, mostrará un mayor empoderamiento. Son esas personas las que encabezarán una reestructuración del entramado social de la vejez sin precedentes y que afectará a toda la sociedad. Estamos convencidos de que el incremento de implicación cívica de los mayores tendrá efectos beneficiosos sobre la calidad democrática de la vida comunitaria y la calidad de vida de cada uno de los ciudadanos.

Consideramos que el estudio presentado es novedoso y que los hallazgos del mismo aportan información relevante acerca del compromiso cívico de la próxima generación de mayores, que no sólo tendrá una gran importancia numérica sino que, plausiblemente, asumirá un importante protagonismo social. Por otro lado, creemos haber aportado averiguaciones valiosas acerca de la importancia que tiene la pertenencia a una determinada generación en lo que respecta a la implicación en los asuntos públicos, frente a frecuentes consideraciones que le atribuyen un mayor protagonismo a la edad cronológica.

\section{Notas}

${ }^{1}$ Citado por Font, Montero y Torcal (2006).

${ }^{2}$ La quinta edición de la ESE 2010-11 no incluye este ítem.

\section{Referencias}

Anduiza, E., M. Cantijoch y C. Cristancho (2010a). Los ciudadanos y el uso de Internet en la campaña electoral. En: Montero J. R. e I. Lago, Elecciones Generales 2008 (pp. 123-142). Madrid: CIS.

Anduiza, E., M. Cantijoch, C. Colombo, A. Gallego y J. Salcedo (2010b).

Los usos políticos de Internet en España. Revista Española de

Investigaciones Sociológicas 129(1), 133-146. Recuperado de http://www.jstor.org/stable/27799036

Astudillo, J. y T. Rodon (2013). El comportamiento electoral del votante en la mediana y las "paradojas" de la competición política española. Revista 
130 Emilia Riesco - Género, Generación e Implicación Política

Española de Investigaciones Sociológicas 144(4), 3-21. Doi:

10.5477/cis/reis/144.3

Barrio, E. (del) y M. T. Sancho (2012). Vida cotidiana, valores, actitudes y la experiencia de envejecer. En: R. Díaz Martín (coord.) Informe 2010. Las personas Mayores en España (pp. 265-324). Madrid: IMSERSO. Beck, U., A. Giddens y S. Lash. (1997). Modernización reflexiva: Política, tradición y estética en el orden social moderno. Madrid: Alianza Universidad.

Bonet, E., I. Martín y J. R. Montero (2006). Las actitudes políticas de los españoles. En: Montero, J. R., J. Font, y M. Torcal, Ciudadanos, asociaciones y participación en España (pp. 105-132). Madrid: CIS.

Castaño, C., J. Martín y J. L. Martínez (2011). La brecha digital de género en España y Europa: medición con indicadores compuestos. Revista Española de Investigación Sociológica 136(4), 127-140. Doi:

$10.5477 /$ cis/reis. 136.127

Castells, M. (2000). La Era de la Información. Vol. I: La Sociedad Red. Madrid: Alianza.

Centro de Investigaciones Sociológicas. Estudios 2559, 2757, 2798, 2807 y 2920. Madrid: CIS.

Colectivo Ioé (2008). Barómetro social de España. Madrid: Traficantes de Sueños.

Durán, R. (2002). Sociedad de la información, mayores y movilización política. Revista Electrónica de Geriatría y Gerontología, 4(2).

Recuperado de www.geriatrianet.com

Durán, R. (2007a) Envejecer y empoderar. Una propuesta analítica. Revista Española de Geriatría y Gerontología 42(5), 293-301.

Durán, R. (2007b) La democracia de nuestro mayores. Compromiso cívico y envejecimiento en España. Revista de Investigaciones Políticas y Sociológicas 6(2), 91-105.

Encuesta Social Europea (ESE) (2002). Primera Edición. Recuperado de http://www.upf.edu/ess/

Encuesta Social Europea (ESE) (2009). Cuarta ola (septiembre de 2008enero de 2009). Recuperado de www.upf.edu/ess/pdf/4aola/resultados/ESS4-tecnicoresultados.pdf

Encuesta Social Europea (ESE) (2012). Resultados de la quinta edición de la Encuesta Social Europea 2010-11. Universitart Pompeu Fabra. 
Recuperado de http://www.upf.edu/ess/_pdf/5aola/Datos/ResultadosQuintaEdicion_FINAL.pdf

Font, J., J. R. Montero y M. Torcal (2006). Perfiles, tendencias e implicaciones de la participación en España (pp. 325-345). En: Montero, J. R., Font, J. y Torcal, M. (eds), Ciudadanos, asociaciones y participación en España. Madrid: CIS.

García Escribano, J. J. y L. Frutos Balibrea (1999). Mujeres, hombres y participación política. Buscando las diferencias. Revista Española de Investigaciones Sociológicas 86(2), 307- 329. Doi: 10.2307/40184154

Gil Calvo, E. (2003). El poder gris. Una forma de entender la Vejez. Barcelona: Mondadori.

Guillemard, A. M. (1988). Le déclin du Social. Formation et crise des politiques de la vieillesse. Paris: PUF.

Gunther, R., J. R. Montero y M. Torcal (2001). Democracy and intermediation: some attitudinal and behavioral dimensions. En: R. Gunther, J. R. Montero y H-J. Puhle (eds), Democracy, intermediation, and voting on four continents. Oxford: Oxford University Press.

Habermas, J. (1998). Facticidad y validez. Sobre el derecho y el Estado democrático de derecho en términos de teoría del discurso. Madrid: Trotta.

Inglehart, R. (1991). El Cambio cultural en las sociedades industriales avanzadas. Madrid: CIS.

Inglehart, R. (1998). Modernización y Postmodernización. El cambio cultural, económico y político en 43 sociedades. Madrid: CIS.

Innerarity, D. (2006). El nuevo espacio público. Madrid: Espasa. Instituto Nacional de Estadística (INE) (2013). Oficina Censo Electoral. Elecciones a Cortes Generales de 20 de noviembre de 2011. Recuperado de http://www.ine.es

Montero J. R. e I. Lago (2010). Elecciones Generales 2008. Madrid: CIS.

Montero J. R. y M. Torcal (1990). La cultura política de los españoles: pautas de continuidad y cambio. Sistema 99, 39-74.

Morán, M. L. y J. Benedicto (1995). La cultura política de los españoles:

Un ensayo de reinterpretación. Madrid: CIS

Offe, C. (1988). Partidos políticos y nuevos movimientos sociales. Madrid:

Sistema. 
132 Emilia Riesco - Género, Generación e Implicación Política

Orizo, F. A. (1996). Sistemas de valores en la España de los noventa.

Madrid: CIS, Siglo XXI.

Pérez Díaz, J. (2003a). La Madurez de Masas. Madrid: IMSERSO.

Pérez Díaz, J. (2003b). Feminización de la vejez y Estado de Bienestar en

España. Revista Española de Investigación Sociológica 104(4), 91-121.

Doi: 10.2307/40184570

Pérez Díaz, J. (2007). La revolución educativa en las generaciones

españolas. Revista de Demografía Histórica 25(1), 137-164. Recuperado de http://hdl.handle.net/10261/41956

Pérez-Díaz, V., A. Abellán y D. Ramiro (2012). Contexto Demográfico, socioeconómico y de salud. En: CSIC, Una vejez activa en España (pp.15-32). Madrid: EDIMSA Editores Médicos.

Pérez Ortiz, L. (2002). Actividades, actitudes y valores. En: Sancho, M.

(coord.), Envejecer en España. II Asamblea sobre el Envejecimiento. (pp. 331-417). Madrid: IMSERSO.

Pérez Ortiz, L. (2005). Actividades, actitudes y valores. En: Sancho, M. (coord.), INFORME 2004. Las Personas Mayores en España. (pp. 547641). Madrid: IMSERSO

Pérez Ortiz, L. (2006). Actividades, actitudes y valores. En Sancho, M.

(coord.), INFORME 2006. Las Personas Mayores en España (pp. 301364). Madrid: IMSERSO.

Pérez Ortiz, L. (2009a). Protección social a la vejez. En: Díaz Martín, R.

(coord.), INFORME 2008. Las personas Mayores en España. (pp. 133176). Madrid: IMSERSO.

Pérez Ortiz, L. (2009b). Comportamiento y actitudes políticas. En: Díaz

Martín, R. (coord.), Las Persona mayores en España. Informe 2008. (pp. 282-287). Madrid: IMSERSO.

Putnam, R. D. (1993). Making democracy work: Civic traditions in modem Italy. Princeton: Princeton University Press.

Putnam, R. D. (ed.) (2003). El declive del capital social. Un estudio sobre las sociedades y el sentido comunitario. Barcelona: Galaxia Gutenberg. Riesco, E. (2009). Envejecimiento en España: percepción, auto-percepción y participación política. En: J. Rivera y E. Riesco (eds), Envejecimiento de la población en España y Japón: Estudio comparativo y posibles implicaciones para Europa y Asia Pacífico. (pp. 175-223). Salamanca: Ediciones Universidad de Salamanca. 
Riley, M. (1985). Age Strata in Social Systems. En: R. H. Binstock y E. Shanas (eds), Handboock of Aging and the social Sciences. Nueva York: Van Nostrand Reinhold.

Riley, M. (1988). Social structure and human lives. Newbury Park: Sage. Sánchez Vera, P. y E. Bódalo (2010). Tiempo ideología y medios de comunicación en la población mayor. En: Giró, J. (coord.), Envejecimiento, conocimiento y experiencia (pp.:191-214). Logroño: Universidad de la Rioja.

Torcal, M. (1995). Actitudes políticas y participación política en España.

Pautas de cambio y continuidad. Madrid: Universidad Autónoma de Madrid, tesis doctoral.

Torcal, M. (2006). Political disaffection and democratization history in new democracies. En: M. Torcal y J. R. Montero (eds), Political disaffection in contemporary democracies. Social capital, institutions and politics. Londres: Routledge.

Trinidad, A. (2006). Estrategias sociales y económicas en los nuevos jubilados. Revista Española de Investigaciones Sociológicas 115(3), 135163. Doi: $10.2307 / 40184769$

Verba, S., N. H. Nie y J. Kim (1978). Participation and Political Equality: A Seven Nation Comparison. Cambridge: Cambridge University Press. Verge, T. y R. Tormos (2012). La persistencia de las diferencias de género en el interés por la política. Revista Española de Investigaciones Sociológicas 138(1), 89-108. Doi: 10.5477/cis/reis.138.89

Emilia Riesco Vázquez es Profesora de Sociología en la Universidad de Salamanca (España)

Contact Address: riesco@usal.es 